\title{
How to make big decisions: A cross-sectional study on the decision making process in life choices
}

\author{
Lucrezia Savioni $^{1,2}\left[\right.$ C Stefano Triberti ${ }^{1,2} \cdot$ Ilaria Durosini $^{2} \cdot$ Gabriella Pravettoni $^{1,2}$
}

Accepted: 25 January 2022

(c) The Author(s) 2022

\begin{abstract}
People often make life choices that will affect their future (e.g. getting married). However, research on decision making focuses more on abstract dilemmas than on decision making. The aim of this study is threefold: to analyze (1) whether people rely mainly on intuitive or rational processing (System 1 or 2) when making life choices; (2) whether some characteristics of recalled life choices (e.g., difficulty in making the decision) differ between life areas (sentimental and work contexts); (3) whether personality traits and System 1 or 2 utilization may predict final satisfaction in life choices. By conducting a crosssectional study on 188 participants' recall of selected life decisions (in the sentimental and work life areas) we found that System 1 is more involved than System 2 in sentimental choices while the opposite happens for work ones. Lastly, satisfaction in life choices is partially predicted by the involvement of cognitive systems and individual differences, with different predictors emerging across life areas. Discussion suggests directions for future research on naturalistic decision making.
\end{abstract}

Keywords Decision making $\cdot$ Life choice $\cdot$ System $1 \cdot$ System $2 \cdot$ Personality traits

\section{Introduction}

Decision making is studied by multiple disciplines, from statistics (Stine et al., 2011) to psychology (Beach \& Connolly, 2005) to economics (Stolyarov et al., 2019). The application impact of these studies is of enormous importance since decision-making processes are transversal to multiple and various contexts, including, for example, the medical, political-economic, organizational, and business fields. At the theoretical level, decision making is a process of making a choice from a number of alternatives to achieve a desired result (Eisenfuhr, 2011). This definition has three key elements. First, decision making involves making a choice from a number of options, resources, opportunities; second, decision making is dynamic, involves a number of factors and sub-processes; thirdly, the "desired result" involves a purpose or target resulting from the mental

Lucrezia Savioni

lucrezia.savioni@unimi.it

1 Department of Oncology and Hemato-Oncology, University of Milan, via Festa del Perdono 7, 20122 Milan, Italy

2 Applied Research Division for Cognitive and Psychological Science, IEO, European Institute of Oncology IRCCS, via Giuseppe Ripamonti 435, 20141 Milan, Italy activity that the decision maker engages in to perform the choice. Two approaches can analyze decision making: normative and descriptive. The first, which underlies much of economic analysis, presupposes that the decision maker has made a rational choice by considering preferences that do not depend on the specific methods to elicit them or on the particular description of the options. This can be a good explanation of how decisions should be made rather than how decisions are actually made. The descriptive approach, on the other hand, assumes that people's choices are often in contrast with each other, suggesting some empirical generalizations that characterize people's decisions (Shafir et al., 2002). So, decision making usually requires evaluating at least two options that differ one from another in one or more respects. The selection of one option at the expense of another requires an individual to put in place an overall assessment of the alternatives, using specific methods of reasoning and information processing (Bailo et al., 2019; Kondylakis et al., 2017; Kou et al., 2014). In most cases, decision making means thinking in conditions of uncertainty: we cannot predict with certainty the future outcome of the available alternatives, but in the best of cases we can only estimate the probability of these outcomes.

Researchers in the fields of psychology and economics generally agree on the importance of two fundamental 
human motivations, namely the desire to reduce uncertainty and the desire to gain advantage (Bentham, 1970); contrary to the first theories, which saw decision making linked to rational choice, today it is known that human decisions are based both on hedonic and emotional motivations and on rational motivations (Cabanac, 1992). Choice behavior should be considered the result of two motivational processes, one more deliberate and focused on wider objectives and the other more instinctive, heavily influenced by emotions (Loewenstein et al., 2015; Mazzocco et al., 2019; Lucchiari et al., 2016).

Several studies have referred to the distinction between two main "faces" of cognition, since Paivio (1990) who distinguished between nonverbal and verbal processes, to type I and type II processes (Kahneman \& Frederick, 2002) to the reflexive system against reflective used by Lieberman et al. (2002) to experiential and rational system (Epstein, 1994, 2003). In other words, multiple theories in cognition highlight that decision making may be based on more immediate or elaborated cognitive processes. In this study we will refer primarily to the widespread theory by Kahneman \& Tversky $(1979,2013)$, which describes the process of decision making in a context of uncertainty. According to the two authors, in a risky condition, a given solution can be reached in a probabilistic way based on empirical evidence violating the principles of economic rationality which, until now, were the basis of the study of the decision making processes.

While intuitive/emotional/automatic vs. rational/cold/ controlled processes are widely studied within experimental studies, there is little research on how they are employed to solve everyday problems and ultimately to make relevant decisions. Do we think intensely when we choose a partner, or do we let emotions guide us? What about when we perform career choices? How do people remember such choices in terms of the cognitive resources involved? The present research aims to provide a preliminary answer to these questions, by asking participants to recall their own life choices in terms of cognitive processes.

\section{Real-Life Decision Making}

Although decision making is a widely studied process, we still know little about how this occurs in "natural" contexts. From the literature we know that when a person has to make a decision, they put in place heuristic strategies (Kahneman $\&$ Tversky, 1974, 1981), but do these also apply when decision making takes place in real life? (Galotti, 1989, 2005, 2007; Pomytkina et al., 2020).

Most literature on people's decision making concerns decision by experts (Klein, 2017; Fortin-Guichard et al., 2020), in which important decisions are made by a group of decision makers who seek consensus (Palomares et al., 2012) or decisions made in simulations and within non-ecological contexts such as the laboratory (Hepler \& Feltz, 2012; Koehler et al., 2015) in which participants receive a series of self-contained, hypothetical decision scenarios, often gambling or games, and are asked to choose from a set of options (Tversky \& Kahneman, 1974, 1981) excluding activities central to life choices such as clarifying goals, gathering information, weighting the relative importance of multiple criteria and without a real impact (Galotti \& Umscheid, 2019; Galotti, 2017; Wiswall \& Zafar, 2015). Life choices are influenced by numerous factors, such as context, social interaction (Sanfey, 2007), and individual differences (Galotti, 2005; Levin et al., 2002;) and can have effects and repercussions on the entire life ahead.

The decision making literature is relatively limited for what regards the study of real life choices due to their complexity and difficulty of measurement (Sanfey, 2007; Rozin \& Hormes, 2010; Beach \& Lipshitz, 2017). First, it is difficult for the experimenter to obtain control over all the variables involved in the decision-making process. In a simulated context, the experimenter could control the main variables and reduce the decision's field to a pseudo-mathematical problem, while decisions taken in everyday life are filled with partiality and uncertainty. Secondly, life choices are important decisions for the subject. Notable attention is put in evaluating the choices in order to make the best one and many factors come into play such as the context in which the decision is taken, the presence and influence of significant others, etc. This cannot happen in the laboratory or within simulations, where subjects are presented with abstract scenarios that can be very far from their daily life (e.g., "imagine you are the chief of an important company...."). When others are involved in simulated/experimental decisions, it is hardly proven that such simulation would be an acceptable modelization of their real-life behavior (Presnilla-Espada, 2014; Bell et al., 2008). Moreover, people will attach different priorities to different goals at different times in their lives which is why, in most real-life cases, there is not one absolutely-correct choice to make (Galotti, 2005). On the contrary, some options may be blurred or unknown, and not all the possible consequences of the choice alternatives are available to the individual when it is the time to choose (Barclay \& Raihani, 2016).

The literature on decision making in life choices often focuses on the outcome of the decision and on how the type of choice is linked to some specific individual factors, such as personality, level of stress and anxiety, etc. For example, Lauriola and Levin (2001) demonstrated that people high in openness to experience take more risks than neurotics; neurotics also perform worse in decision making especially when they have to decide under pressure (Byrne et al., 2015), while extraverted people may be too confident in their choices (Schaefer et al., 2004) but also more cooperative and altruistic (Hirsh \& Peterson, 2009; Tao et al., 2020). Hartley 
and Phelps (2012) stressed how anxious individuals' daily decision-making is influenced by their excessive fear and concern. However, there is a lack of literature on how the decision making process takes place, that is, on the cognitive resources that people put into play when they elaborate a certain decision and when they select the course of action to be implemented. This is related to the difficulty inherent to reproducing a complex life context in the laboratory simulation, as well as to the inadequacy of observational tools to capture fine-grained processes such as the cognitive ones involved in decisions. Our goal is to investigate life choices broadly and focus on some relevant factors that can influence the life choices.

Specifically, This study investigated the "love"/affective sphere and the "work"/career sphere; these should not be considered a complete representation of human life, yet it could be sustained that significant decisions taken in these two life areas are virtually common to the life of any adult person. In terms of previous research, for example, Hazan and Shaver (1990) implemented multiple studies where participants were surveyed about "love and work" in their lives to assess the main hypothesis that the two areas were functionally similar to attachment and exploration in early childhood, and to analyze their reciprocal influences and effects on well-being.

\section{Affect Vs. Reasoning in Life Choices}

As said above, psychological literature often represented decision making as a process influenced by two "forces" or "systems", one more rational and deliberative, that, following Kahneman and Frederick (2002), we will call System 2 and the other emotional and intuitive that we will call System 1 (Sloman, 1996; Stanovich \& West, 2000; Pacheco-Barrios $\&$ Fregni, 2020). System 2 is rule-based, operates willfully and is effortful most of the time. It tends to be controllable, conscious and slow (Evans \& Stanovich, 2013; Stamos et al., 2018). System 2 makes decisions based on liking and is more reactive and long-term goal-oriented (Loewenstein et al., 2015). System 1 is quick and heuristic-based (Stamos et al., 2018); it works automatically and operates mainly through the components of the associative memory, therefore different associations tend to emerge spontaneously and influence behavior (Evans \& Stanovich, 2013). System 1 makes decisions based on wanting and is influenced by emotions and short-term drives (Loewenstein et al., 2015).

Despite their differences, the two systems do not operate in isolation, but simultaneously. Sometimes intuition will have more weight in the decision, other times rationality will be more responsible for the choice (Dhar \& Gorlin, 2013; Levine, 2019; Khatri et al., 2018). Also, the influence of the stimulus could be similar or different for the two systems. For example, if there are similar motivational tendencies "during a break at a conference, the availability of a snack might create a surge of hunger in the affective system and be perceived by the deliberative system as a welcome opportunity to recharge before the next session" (Loewenstein et al., 2015 , p. 58). In other cases, in which the effect of the stimuli is different "if the conferee is on a diet, for example, the availability of the snack might also remind her of that fact, leading to a divergence of affective and deliberative motivation" (Loewenstein et al., 2015, p. 58) Different studies on the use of System 1 System 2 during the decision making evidenced that people tend to choose an option that is somewhere in between the deliberative optimum and the affective optimum.

Also the emotions play a pervasive and predictable role in decision making and satisfaction (Côté \& Morgan, 2002). A recent review showed (Lerner et al., 2015) that emotions are the dominant driver of most meaningful decisions in life (Loewenstein et al., 2001; Ekman \& Yamey, 2004; Oatley et al., 2006) leading the individual to focus on information congruent with the felt emotion, and consequently to a biased interpretation of the stimulus or the event producing a distortion in risk perception and, consequently, suboptimal decisions (Finucane et al., 2000).

\section{The Role of Context in Choices}

Choices are often not made in isolation, but decisions occur in the family and in wider social contexts (Ben-Akiva et al., 2012; Chao et al., 2021). Especially, when decision regards important life paths, they are influenced by the "realm" in which they happen; if I have to take a decision regarding my work or my degree program, I know this could affect my self-realization and possibly my future wealth; if I have to take a decision regarding love and family, I know this would affect my future relational and social well-being. Obviously, paths chosen in life intertwine and influence one another, for example pursuing some career will have an impact on one's family life and vice versa. Yet, it is possible that people would first consider the possible consequences more salient in a certain life area, and this could have an influence on the decisional process as a whole (e.g., taking emotions more or less into consideration to orient the choice). Career research and college selection, for example, show that deciding which type of job or which type of degree program is tied to the best use of your talent and ability, job security and high income, good social status, etc. (Ngambeki et al., 2008). This suggests that career or university choices can be made with a greater use of the deliberative system (System 2 ). Of course this does not mean that the more intuitive, emotional System 1 is not involved in career choices. Indeed, if we would accept the "homo oeconomicus" approach to motivation and decision to work (i.e., workers are motivated by earnings only), it would be impossible to explain 
motivation's components such as enthusiasm and interest (Bojanić, 2014). Work and career often hold important emotional and identitary value which act as motivators to pursue it (Meijers et al., 2013; Yang, 2019). Yet, many studies in career choice and job orientation emphasize that a career choice should be made based on rational and careful evaluation of alternatives and possible consequences, rather than instinctively. For instance, university degree choice appear to be influenced by a mixture of interest towards the subject, high or low worry for one's own future, attitude towards helping others and the preference for easy choices (loafing) (Skatova \& Ferguson, 2014), which tend to be investigated by dedicated questionnaires and point towards attentive and explicit evaluation of alternatives before taking a decision. Also the extensive research from the person-environment fit theory (Van Vianen, 2018; Guan et al., 2021; Riedo et al., 2019), which tenets that decisions are optimal when personal attributes (e.g., needs) and environmental attributes (e.g., supplies) are compatible, emphasizes that career choices are based primarily on careful evaluation of one's own and the organization's characteristics.

Research on love and relationships shows that people decide for a relationship taking into account aspects such as eros and commitment, satisfaction and the previous relationships experiences (Hammock \& Richardson, 2011). It is possible that life decisions about loved ones and relationships would imply a greater use of the intuitive system (System 1), especially in virtue of System 1's intrinsically emotional component and instinctive nature, at least if compared with career/job choices. Since in the present research participants will be asked to report on their recollection of significant life choices, it is possible they will be keen to find a more prominent role of emotions, intuition and instinct in their own life choices related to love and affection. An interesting example is the work by Dailey and colleagues (Dailey et al., 2009), who employed a qualitative research methodology to describe reasons for break ups or renewals of romantic relationships: their results show a number of themes that could be considered "irrational" and impulsive, such as decisions based on feelings independent of reasoning (e.g., "I just didn't feel like marrying anymore") or cognitive dissonances related to one's own behavior (e.g., cheating after having decided not to, and feeling guilty after).

It should be said that many factors could be considered that would make such a line of reasoning appear as an oversimplification. One could marry with the aim to achieve specific advantages, e.g. governmental incentives, access to wealth or international citizenship (Ash \& Badgett, 2006; Wray, 2006; Maskens, 2015; Hatch, 2017; Pilgeram $\&$ Amos, 2015), deciding on the sentimental life area in a cold/rational fashion; on the contrary, one could be driven towards the selection of a job by the necessity to regulate emotions and stress (Firth et al., 2004;) or also by authentic passion for it (Smith \& Manna, 2005). We will hypothesize that Systems 1 and 2 will be associated to a greater extent respectively to the sentimental and the work-related life choices, at least in terms of recollection, taking into account the literature outlined above but also the complexity of life choices as they develop in real life scenarios.

\section{The Role of Individual Differences}

Several constructs can be interesting for investigating decision making in different life choices' contexts. Many studies in applied psychology show that individuals' attitudes and choices are influenced by personal tendencies or personality traits (Lauriola \& Levin, 2001; Byrne et al., 2015). For example, when people make school or career choices, high levels of neuroticism are associated with a less experience of difficulties in making decisions (Gati et al., 2011; Di Fabio \& Palazzeschi, 2009). The studies of partner' choice are focused on the personality traits that could be helpful in mate searching. For example, Back and colleagues (Back et al., 2011), found that extraversion is associated with a more active flirting behavior and therefore a greater possibility of finding a partner, as opposed to shyness.

The literature about perceived social support highlights that people who experienced decision in a supportive context have a higher decisional competence and lower decisional conflict (Lawson \& Pierson, 2007). For example, Chen et al. (2018) evidence that, in women who have to decide whether to undergo prenatal screening or not, social pressure decreases the satisfaction of the choice while they tend to experience greater confidence and satisfaction in the choice made if it occurred in a context of social support. It is widely acknowledged that high perceived social support is positively related to career satisfaction and expectations (Franco et al., 2019; Roxburgh, 1999; Isik, 2013), as well as to close relationships' success and marital quality (Dehle et al., 2001; Lin et al., 2017), as it acts as a buffer against stress and negative emotions. In this sense, it is possible that people experiencing a desirable level of social support would be more confident in their choices in life and even more satisfied, as they are reinforced and supported by their loved ones. Wray and Stone (2005) have studied the role of anxiety in decision making. In their studies, they found that subjects who show higher anxiety levels tended to make riskaverse personal choices, but not in others' decisions. According to literature, anxiety affects decision because its makes risks and possible negative outcomes of choices more salient in the decision maker's perception (Sebri et al., 2021; Noël et al., 2013; Cavanagh et al., 2014; Herman et al., 2018), so that final decisions may be conservative and/or orientated to avoid risks and punishments more than obtaining distant positive outcomes. 
As mentioned above, all life choices are influenced by the context and relationships with others, as the choices are made within a society and for this reason, they can influence both one's own and others' lives. Some theories argue that the way we approach relationships is influenced by how we build relationships during the first few years of life (Hamarta, 2004). According to attachment theory (Bowlby, 1973, 1982) people develop internal behavior patterns related to the relationships they have experienced with reference figures during infancy, childhood and adulthood. According to Bowlby (1973), an individual's initial attachment is established from the beginning of his development through the relationship with his primary caregiver(s), and this provides a cognitive framework for his subsequent social relationships.

Since attachment is a precursor to our future relationships, this could also influence how we make decisions in multiple life areas, since those hold important consequences for the quality of present and future social life (e.g., building a family, collaborating with new coworkers, etc.). A study on 567 students found that attachment style significantly predicts decision making style. In particular, the authors have seen that the secure attachment style is the most significant predictor of procrastination, buck-passing and vigilance decision making styles and decision self-esteem; while fearful attachment style was found to be the most significant predictor of hypervigilance decision making style (Deniz, 2011). Furthermore, a study (Hazan \& Shaver, 1990) demonstrated that attachment style was related to decisions and behavior in the "love and work" life areas as adults; specifically, secure-attached adults approach their work with more confidence but attribute more importance to affective relationships; ambivalent-attached respondents were more preoccupied that love concerns would interfere with their work performance, and feared the consequences of poor work performance the most; finally, avoidant-attached persons were found to value their career as they use it to reduce social interactions, and were also the less satisfied by it.

\section{Objectives}

The present study aims to explore the cognitive mechanisms involved in important life choices that are identified by the participants themselves. Specifically, we will ask participants to recall significant choices they made in their life-time, specifically two types of choices: sentimental (e.g., "Should I get married?"; "Should I break up with my partner?") and work (e.g., "Should I move abroad for work?"; "Should I accept that job offer?"). It should be noted that while a processual analysis of decision (Abbey $\&$ Valsiner, 2005; Fossa et al., 2016) in life choices is probably impossible to carry out (i.e., a step-by-step analysis of micro-components of decisions would require collecting data on the life-relevant decision the moment/period they are taken, and with very complex tools), it is still feasible to collect information on people's recollection of decisions and the factors involved in them.

This considered, the first aim of this study is to evaluate the differences in terms of System 1 and System 2 usage within life-relevant decisions taken regarding different life areas (i.e., Love/relationships and Work/career). The second objective of the study is to explore the relations between employment of System 1 and 2 in life choices and personality traits or personal tendencies. The third objective of the study is to analyze whether some characteristics of the recalled life choices (namely difficulty in taking the decision, pleasantness of the decision process, current memory ("clarity") of the decision process, final satisfaction) differ between life areas. Fourth objective of the study, as related to the outcome of the choice, would be to analyze the predictive relationships between personality traits and utilization of System 1 and 2 as predictors, and final satisfaction for the life choice in the two areas.

Research hypotheses and research questions are as follow:

Hp1: People will tend to make more use of rational and deliberative system (System 2) in career choices, while for choices in the emotional sphere, they will tend to make more use of the more emotional and intuitive system (System 1).

Rq1: We will explore the differences between sentimental and work choices in terms of clarity of the decision recollection; difficulty to take the decision; pleasantness of the decision process; and satisfaction regarding the final choice.

Rq2: We will explore whether individual characteristics of participants and the utilization of System 1 and 2 predicted satisfaction with the decisions in the two life areas.

\section{Methods}

\section{Participants}

A total of 188 Italian adults were included in this study. $24.5 \%$ were male $(n=46$; female: $n=142)$ and ages from 19 to 63 years old $\left(M_{\text {age }}=31 ; S D_{\text {age }}=8.21\right)$. The majority of them were employed and were bachelor or maiden. All the participants consented to participate voluntarily and did not receive incentives for their participation.

\section{Materials and Procedures}

Participants were invited via social media and mailing list to take part in this study. We used snowball sampling based on 
respondents and researcher networks (Biernacki \& Waldorf, 1981): "Snowball sampling yields a study sample through referrals made among people with important characteristics for the research question. It is particularly applicable when the focus of study is on a sensitive issue, and thus requires the knowledge of insiders to locate people for study." Data were collected from October 2019 to April 2020. Informed consent was obtained prior to the questionnaire completion and the anonymity was protected for all participants. The survey was set on a Google Moduli platform. After having provided socio-demographic information, participants were invited to think about autobiographical memories, and specifically to (a) one specific relevant choice pertaining to the professional area, and (b) one specific relevant choice pertaining to the sentimental area. Specifically, participants were invited to think about "an event or a specific experience of your life in which you had to make an important decision. In particular, think of an event experienced in your life regarding the affective sphere (e.g., Should I get married? Now or later? Should I leave my partner? Should we go to live together?)" and to think about "a specific event or experience of your life in which you had to make an important decision. In particular, think of an event experienced in your life concerning the professional area (e.g., Should I study or work? Should I move for work? Which job/university should I choose?)". After each request, participants were asked to indicate the clarity (e.g., How clear is the episode?) and pleasantness (e.g., How enjoyable was this episode?) of the evoked episode, the difficulty (e.g., It was difficult to decide) experienced when making the choice, the personal satisfaction (e.g., As of today, I am satisfied with my choice) related to the final choice on a 7-point Likert scale, and the days that participants spent to make a decision. Participants were also invited to indicate if they used System 1 or System 2 to make their choices on a 7-point Likert scale (from strongly disagree to strongly agree). The use of System 1 was assessed through two items: "To decide, I relied on intuition, inspiration" and "To decide, I let my emotions guide me". While the use of System 2 was explored with these two items: "To decide, I relied on reasoning" and "To decide, I documented on all the possible options". These questions were selected based on literature, to represent the distinctive characteristics of Systems 1 and 2 when solving problems and taking decisions: an example of similar questions could be found in trait-based questionnaires that measure individual's tendency to rely more on rational or experiential processes, such as the REI (Pacini \& Epstein, 1999; Richards et al., 2018). Lastly, the following self-report questionnaires have been administered in order to assess participants' psychological aspects:

- State-Trait Anxiety Inventory (STAI-Y-2; Metzger, 1976; Spielberger et al., 1983; Italian validation:
Pedrabissi \& Santinello, 1989): STAI-Y-2 is a self-report instrument commonly used for the measure of trait and state anxiety. In this study, we administered only the 20-items related to the trait anxiety (4-point likert scale from "for nothing" to "very much"). STAI-Y-2 can be used in clinical settings to diagnose anxiety in adults and distinguish it from depressive syndromes. The scale showed a good reliability equal to .86 (Spielberger et al., 1983). In this study, the scale showed a good reliability equal to .92 .

- Rosenberg Self-Esteem Scale (RSES; Rosenberg, 1965, 2015; Italian validation: Prezza et al., 1997): RSES is a 10-item self-report scale to measure self-esteem. It is a Guttman scale rated on a 4-point likert scale from "strongly disagree" to "strongly agree". The items explore the individual's satisfaction with himself/herself, positive, and negative feelings. The scale showed a reliability equal to .84 (Prezza et al., 1997) and in this study, the reliability is equal to .87 .

- Big Five Inventory (BFI; John et al., 1991; Italian validation: Ubbiali et al., 2013): BFI is a self-report questionnaire that assesses personality traits through 44 -items. It explores five dimensions of personality: Openness to experience, such as curious, imaginative, and artistic people; Conscientiousness, such as efficient, organized, and thorough people; Energy or Extraversion such as sociable, energetic, and enthusiastic people; Agreeableness, such as forgiving, warm and sympathetic people; and Neuroticism, such as tense, irritable, and moody people. Items are assessed on a 5-point scale ranging from "strongly disagree" to "strongly agree". In the present study, the scale revealed an acceptable internal validity (extraversion: $\alpha=.86$; agreeableness: $\alpha=.68$; neuroticism: $\alpha=.83$; consciousness: $\alpha=.82$; openness to experience: $\alpha=.85$ )

- Multidimensional Scale of Perceived Social Support (MSPSS; Zimet et al., 1988; Italian validation: Prezza \& Principato, 2002): MSPSS is a self-report questionnaire that explores the perceived social support. The scale is composed of 12 items on a 7-point likert scale ranging from 1 (strongly disagree) to 7 (strongly agree). The instrument measures support from family, friends, and significant others. The scale showed a good reliability equal to .88 (Zimet et al., 1988) and, in this study, the reliability was equal to .91 .

- Measure of Attachment Questionnaire (MAQ; Carver, 1997; Italian validation: Roccato \& Tartaglia, 2003): MAQ is a 14-items each rated on 4-points Likert scale (ranging from "strongly disagree" to "strongly agree"). The questionnaire identifies four dimensions, which correspond to the four styles of attachment identified by Carver: Avoidant (anxiety and anger relationships, tendency to seek emotional distance from others), 
Ambivalent-Worry (fears of abandoned or relationship betrayal; positive view of self, negative view of other), Ambivalent (desire for closeness, preoccupation; negative view of self, positive view of other), and Secure attachment (confidence in others and capacity for intimacy). The scale showed a good reliability of the scales between .69 and .76 (Carver, 1997). In the present study, the scale revealed a good internal validity (Avoidant $\alpha=.81$; Ambilent_Worry $\alpha=.73$; Ambivalent $\alpha=.71$; Secure $\alpha=.84$ ).

\section{Data Analysis}

First of all, a factor analysis was performed in order to determine that the items used to investigate utilization of System 1 (related to intuition and emotion) and System 2 (related to rationality and attentive consideration of available options) to show their internal consistency over two different factors. A Principal Component Analysis with Varimax rotation was conducted with SPSS software (Version 20.0). Principal components analysis (PCA) is one of a family of techniques for taking high-dimensional data, and using the dependencies between the variables to represent it in a more tractable, lower dimensional form, without losing too much information. PCA is one of the simplest and most robust ways of doing such dimensionality reduction. In PCA, the variables under consideration are transformed into a new set of variables, which are linear combination of the original variables (Frey \& Pimentel, 1978).

Additionally, three subsequent analyses were carried out:

- Analysis of Variance $(2 \times 2$ design $)$ was conducted to identify whether intuition and emotion (System 1) and rationality and attentive consideration of available options (System 2) had been preferentially involved across the explored life choices. Data allow us to compare the involvement of System 1 and System 2 across the life choices in the sentimental vs. work life areas. The Analysis of Variance is a statistical technique for analyzing measurement depending on several kinds of effects operating simultaneously, to decide which kind of effects are important and to estimate the effects (Scheffe, 1999).

- A within-subjects $t$-test analysis was conducted to assess the differences between sentimental and work choices in terms of clarity of the decision memory, difficulty to take the decision, pleasantness of the decision process, and satisfaction regarding the final choice. This analysis is widely used to compare groups' means for particular variables (Kim, 2015)..Data allows us to compare the characteristics of the participants' decisional processes when confronting one specific relevant choice pertaining to the sentimental and work life area.
- Regression analyses have been performed to analyze whether individual differences and the utilization of System 1/2 influenced final satisfaction with the choice in the two life areas. Regression allows us to examine the relationship between variables, estimating a numerical value, providing information both at a predictive and descriptive level (Porter, 1999). Individual differences chosen as predictors were based on researchers' hypothesis and literature review. Specifically, to predict satisfaction in the sentimental choice, besides the utilization of System 1 and 2, we tested the subscales of MAQ, because attachment style has been found related to affective relationship quality in the literature (Feeney \& Noller, 1992; Meyer et al., 2015; Smith \& Klases, 2016; Raffagnino \& Puddu, 2018). Differently to predict satisfaction in the work choice, besides the utilization of System 1 and 2 , we tested trait anxiety and self-esteem, because these individual traits have been frequently associated with subjective and objective success in the workplace (Mughal et al., 1996; Baumeister et al., 2003; Judge \& Bono, 2001; Liu et al., 2017; Rogante, et al., 2019). Further regression models were run to explore the possible role of personality traits as predictors of satisfaction with the decisions.

\section{Results}

The present study explored the cognitive processes involved in life-relevant decisions. Participants were invited to report on characteristics of their own decisional processes when confronting one specific relevant choice pertaining to the sentimental or work life area. Initially, a factor analysis was performed in order to determine if items used to investigate the use of System 1 and System 2 showed an internal consistency over the two different factors. For sentimental area, the two-factors solution accounted for $69 \%$ of the total variance. The first factor (defined by two items) refers to intuition and emotion in relationship (System 1) and explains the $40 \%$ of the variance. The second factor (defined by 2 items) refers to rationality and attentive consideration of available options in relationship (System 2) and explains the $29 \%$ of the total variance. In a similar way, for the professional area, the two-factors solution accounted for $75 \%$ of the total variance. The first factor is composed by two items and explains the $45 \%$ of the variance. Items included in this factor were related to the intuition and emotion used to make decisions in professional context (System 1). The second factor is composed by two items and explains the $30 \%$ of the variance. It refers to the tendency to use rationality and attentive consideration of available options during decision making at work (System 2; Table 1). 
To respond to the first objective of the research, ANOVA was performed to identify whether System 1 (reference to intuition and emotion) and System 2 (reference to rationality and attentive consideration of available options) had been preferentially involved across the life choices in the sentimental vs. work life areas. Results highlighted a statistically significant interaction effect between variables $\left(F(1,2687)=69.768, p<.001, \eta^{2}=.272\right)$. Data also showed that System 1 is significantly more involved in the sentimental area $(M=5.3 ; S D=1.46)$ than in the work area $(M=4.7 ; S D=1.53)$, while System 2 is significantly more involved in the work area $(M=5.3 ; S D=1.28)$ than in the sentimental area $(M=4 ; S D=1.75 ;$ Fig. 1$)$.
To respond to the second objective of the study, the two areas were compared, by performing a paired samples $t$-test analysis. No significant differences emerged between sentimental/work choices in terms of clarity of the episode in memory, difficulty to take the decision, satisfaction regarding the final choice. A significant difference emerged regarding pleasantness of the decisional process, with work choices being recalled as more pleasant than sentimental choices (see Table 2 for results).

The third objective of the research was to analyze predictors of the outcome of the choice (e.g., satisfaction with the choice) among personality traits and the utilization of System 1 and System 2 cognitive processes. The first
Table 1 Factor loadings from Principal Component Analysis with varimax rotation

Fig. 1 The use of System 1 and 2 in sentimental and work area

Table $2 t$-tests on decisional processes across sentimental/ work life choices

\begin{tabular}{llllll}
\hline \multirow{2}{*}{ Item } & \multicolumn{2}{l}{ Sentimental area } & & \multicolumn{2}{l}{ Professional area } \\
& System1 & System2 & & System1 & \multicolumn{2}{l}{ System2 } \\
\hline To decide, I relied on intuition, inspiration & $\mathbf{8 4 5}$ & .136 & & $\mathbf{. 8 6 8}$ & -.020 \\
To decide, I let my emotions guide me & $\mathbf{7 5 7}$ & -.300 & & $\mathbf{. 8 8 7}$ & -.129 \\
To decide, I relied on reasoning & .008 & $\mathbf{. 8 0 1}$ & & .070 & $\mathbf{. 8 6 1}$ \\
To decide, I documented on all the possible options & -.119 & $\mathbf{. 8 4 6}$ & & -.239 & $\mathbf{. 8 1 0}$ \\
\hline
\end{tabular}

Factor loadings $>.35$ are in boldface

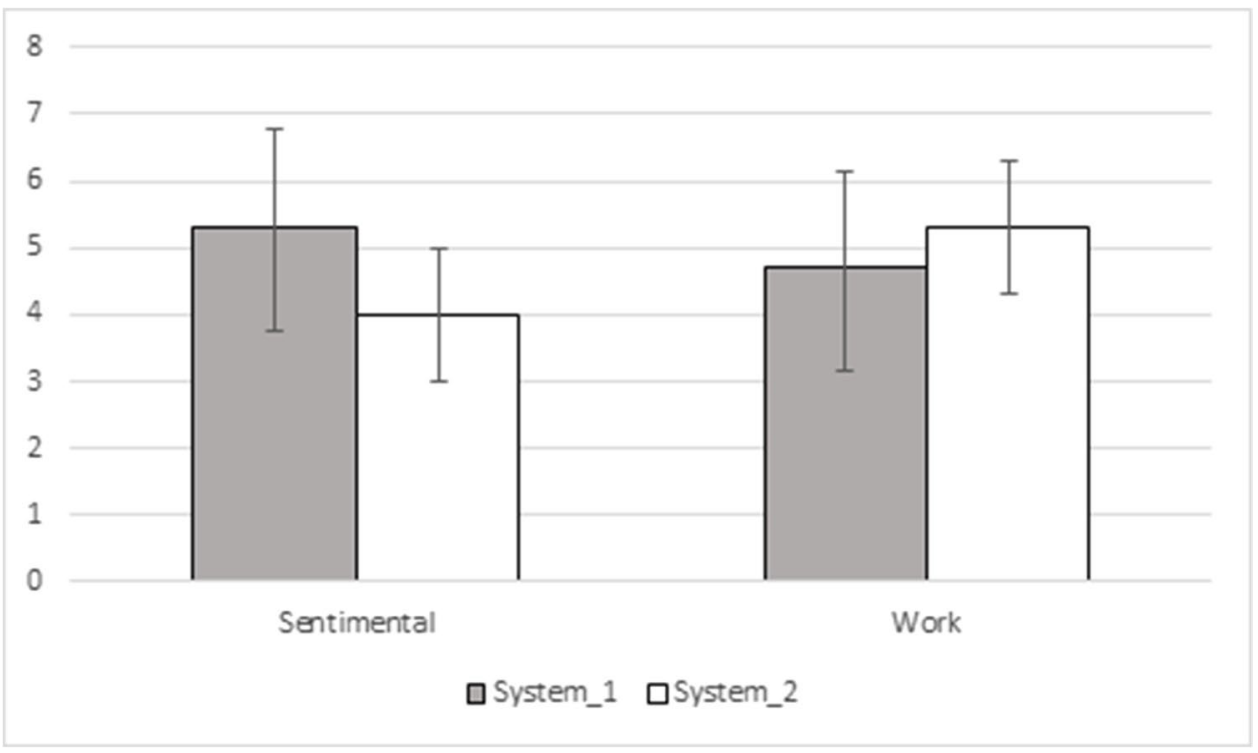

\begin{tabular}{llllll}
\hline & Sentimental $(M, S D)$ & $\begin{array}{l}\text { Work } \\
(M, S D)\end{array}$ & $t$ & $p$ & Cohen's d \\
\hline Clarity of the episode & $6.11,1.1$ & $5.93,1$ & -1.692 & .09 & .17 \\
Difficulty to take decision & $5.07,1.9$ & $4.74,1.6$ & -1.782 & .07 & .18 \\
Satisfaction with final choice & $5.88,1.6$ & $5.62,1.7$ & -1.572 & .11 & .15 \\
Pleasantness of decisional process & $3.4,2.3$ & $4.18,1.8$ & 3.705 & $.00^{* *}$ & .37 \\
System 1 & $5.37,1.4$ & $4.75,1.5$ & -4.255 & $.00^{* *}$ & .41 \\
System 2 & $4.01,1.7$ & $5.38,1.2$ & 9.215 & $.00^{* *}$ & .89 \\
\hline
\end{tabular}


regression analysis focused on satisfaction in the sentimental area. Satisfaction was predicted by secure attachment (positively) and by ambivalent attachment (negatively), with an explained variance of $14 \%$. The second regression analysis focused on satisfaction in the work area. Satisfaction was predicted positively by both System 1 and System 2 , and negatively by trait anxiety, with an explained variance of 15\% (see Table 3 and Fig. 2 for results). Satisfaction in both sentimental and work areas was not predicted by the Big Five personality traits.

Table 3 Regression analyses on sentimental and work choice satisfaction

\begin{tabular}{llllll}
\hline & $B$ & $\mathrm{SE}(B)$ & Beta & $t$ & $p$ \\
\hline $\begin{array}{l}\text { DV: Sentimental choice } \\
\text { satisfaction }\end{array}$ & & & & & \\
$\quad$ System 1 & .065 & .065 & .058 & .821 & .412 \\
System 2 & .089 & .079 & .095 & 1.371 & .172 \\
Secure Attachment & .611 & .187 & .252 & 3.260 & .001 \\
Avoidant Attachment & .120 & .187 & .051 & .640 & .523 \\
Worried Attachment & -.246 & .149 & -.124 & -1.644 & .102 \\
Ambivalent Attachment & -206 & .180 & -.258 & -3.365 & .001 \\
$F=5.203 ; p<.001 ;$ & & & & & \\
$R^{2}=.14 ; N=188$ & & & & & \\
DV: Work choice satisfaction & & & & & \\
System 1 & .205 & .079 & .178 & 2.582 & .011 \\
System 2 & .260 & .095 & .190 & 2.744 & .007 \\
Trait Anxiety & -.049 & .016 & -.320 & -3.109 & .002 \\
Self Esteem & -.007 & .031 & -.023 & -.226 & .822 \\
$F=8.568 ; p<.001 ;$ & & & & & \\
$R^{2}=.15 ; N=188$ & & & & & \\
\hline
\end{tabular}

\section{Discussion}

This study aims to explore the cognitive mechanisms involved in important life choices. We explored the cognitive processes involved in life-relevant decisions asking participants to report the characteristics of their own decisional process when they had to make an important choice in two life areas. Specifically, we assessed the use of an intuitive (System 1) and rational (System 2) decisional process in sentimental and work life areas. The factor analysis showed an internal consistency over the two factors in each area, supporting the existence of two different cognitive decision-making systems in the explored life contexts.

Our results showed that people tend to use System 1 (reference to intuition and emotion) more when they have to make a decision in the sentimental area. When people have to make decisions in love, they tend to listen more to their feelings than to use rationality; for example, in the decision whether to marry the partner one has been with for several years and has built a solid relationship with, feelings and emotions come into play at a stronger extent (Franco \& Sanches, 2016; Lee \& Selart, 2012). When, instead, one has to make a decision regarding job and employment, analytical reasoning appears to be involved more. In this context, the subject tends to carefully evaluate situations and the pros and cons of the decision outcome. While this does not mean people exclude careful reasoning when dealing with sentimental matter or stop listening to emotions and insight when it comes to work-related choices, results clearly show that individuals have a specific recalling of the characteristics of cognitive processes involved in important life choices, which can
Fig. 2 A graphic representation of the regression models on life choices' satisfaction

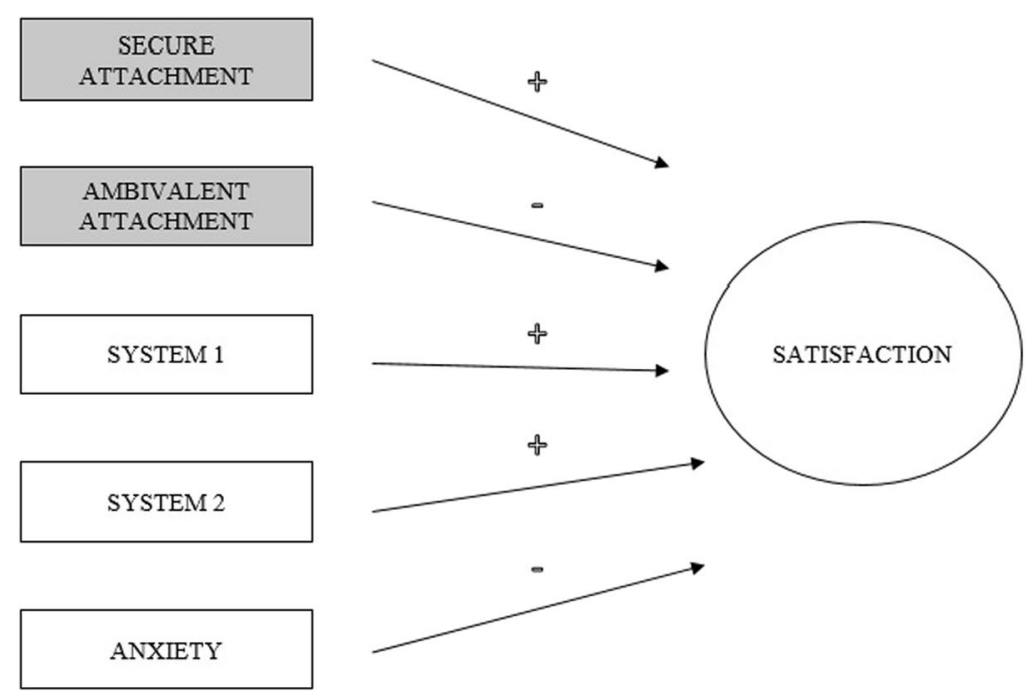

$\square \quad$ Sentimental area
$\left(\mathrm{R}^{2}=0.14\right)$
$\square \quad \begin{aligned} & \text { Work area } \\ & \left(\mathrm{R}^{2}=0.15\right)\end{aligned}$ 
be described in terms of System 1 or System 2 processes (Hertwig \& Erev, 2009; Ludvig \& Spetch, 2011).

The analysis of some characteristics of recalled life choices in the different life areas showed a difference only regarding pleasantness: decisions in the work area are remembered as more pleasant than sentimental decisions. This result alone is not easy to interpret. On the one side, it is possible that life choices in the sentimental area involve a wider variety of emotions and they underwent more dramatic elaboration and emotion regulation efforts. An alternative interpretation may regard a memory bias that leads subjects to remember extreme results sooner and more frequently (Madan et al., 2014; Wagoner et al., 2020). We can therefore assume that career choices involve a higher level of risk for one's own future than sentimental ones, because they may potentially lead to outcomes more difficult to change at a later time (e.g., moving abroad); this characteristic leads them to be remembered more pleasantly, because the decision process involved more risk, and the participants are today happier to have overcome such obstacles.

Individual characteristics as well as the recourse to rational vs. intuitive cognitive processes proved to play a role in the final satisfaction about the outcome of the choice. Despite explained variances being relatively low, regression analyses provided some interesting information. On the one hand, satisfaction with sentimental life choices is predicted by attachment style. This supports existing literature (Akpan \& Ottu, 2011; Bradford et al., 2019; Jones \& Cunningham, 1996; Kirkpatrick \& Davis, 1994) as well as the idea that intimate relationships are influenced by affective experiences that could be traced back to early life development. Apparently, in sentimental life choices these preexisting dispositions are more relevant in influencing final satisfaction than the cognitive processes utilized to decide. On the other hand, satisfaction with choices in the work area is predicted negatively by trait anxiety, which again is consistent with previous literature that shows that anxious people are more vulnerable to work related stress and dissatisfaction (Extremera et al., 2020; Saquib et al., 2019), and also positively by the usage of both System 1 and System 2 cognitive processes when taking the choice. This last result shows that, despite the possibility to utilize more one system or the other when deciding, the final outcome of a life-relevant decision may be determined by a complex decision process, which features both careful assessment of options and intuitive/emotional influences.

Decision making is widely studied by different disciplines, but studies are often focused on abstract dilemmas, leaving out its study in the "natural" contexts of life choices. This research can contribute to this field. Findings show that the decision-making process changes in relation to various variables, both personal (e.g., personality characteristics, anxiety traits, attachment style, etc.) and the type of choice that one has to make (e.g., sentimental or work-related). The information provided in this study can be a starting point for future research on decision making in life choices. In fact, there are several aspects that can be investigated and that can be useful for greater knowledge of "naturalistic"/ life-relevant decision making, which have not been taken into consideration in the present study. For example, the recourse to cognitive strategies more or less influenced by emotions may be influenced by emotion regulation strategies. Moreover, contextual factors deserve recognition in this area, for example the advice or influence of significant others may affect both decision outcomes and the process to reach them. At the same time, this study also has some limitations. The questionnaire-based method we employed allowed us to recognize and analyze some aspects of liferelevant choices, but these could not be studied in detail in the laboratory (maybe only simulated); for this reason, this study lacks the controllability that could be guaranteed by experimental settings. Furthermore, we did not compare specific life choices but let participants focus on the recollection of personal examples across life areas; so what was studied is the recollection of the decision, which leaves out the analysis of contingent factors such as emotions felt at the time of decision making. This may have led to uncontrollable variability in the sample choices, but it allowed us to study the authentic life-relevant decisions as any individual person recollected to make them. Secondarily, it could be noticed that recollection of a choice, especially an important one like those investigated in the present study, may be a partially distorted representation of the actual decision process, as it was plausibly modified through narration and introspection over time. Further research would be needed to analyze how much recollection of a life decision could be considered a faithful representation of the original decision process. Future research may explore further the adequacy of such a methodology to similar research aims. Another limitation may be found in how the study questions were formulated, as we asked participants to report whether reasoning or emotions were a dominant factors in important life choices: admitting that one decided to marry for merely rational/strategic reasons could be considered antisocial and morally despicable, as well as admitting that one has chosen a given career due to emotions only may be considered impulsive and foolish. This could drive some participants to alter their responses to put themselves in a positive light and/or to not experience cognitive dissonance, so we cannot rule out that demand characteristics partially influenced participants' responses. Future research may employ questions formulated differently, e.g.just asking participants to think of a moment in life where they evaluated what they wanted in a partner/job, prior to decisions. Furthermore, the sample size is limited. Similar methods could be employed with larger samples, balanced by gender and other relevant demographic 
characteristics, to capture additional information on how people take important choices in their everyday life.

Acknowledgments LS is a Ph.D. student within the European School of Molecular Medicine (SEMM). ID was supported by Fondazione Umberto Veronesi. ST and GP were supported by MIUR - 698 Italian Ministry of University and Research (Departments of Excellence Italian Law n.232, 699 11th December 2016) for University of Milan.

Authors' Contributions LS conceived the ideas presented in the article, conducted the study and wrote the first draft. ST supervised the research, contributed to data analysis and edited the manuscript. ID contributed to data analysis and edited the manuscript. GP edited the manuscript and supervised the whole process.

Data Availability The data from this study will be available from the corresponding author upon request.

Code Availability Not applicable.

\section{Declarations}

Ethical Approval All procedures performed in studies involving human participants were in accordance with the ethical standards of the institutional and/or national research committee and with the 1964 Helsinki Declaration and its later amendments or comparable ethical standards.

Informed Consent Informed consent was obtained from all individual participants included in the study.

Conflict of Interest The authors declare that there are no conflicts of interest.

Open Access This article is licensed under a Creative Commons Attribution 4.0 International License, which permits use, sharing, adaptation, distribution and reproduction in any medium or format, as long as you give appropriate credit to the original author(s) and the source, provide a link to the Creative Commons licence, and indicate if changes were made. The images or other third party material in this article are included in the article's Creative Commons licence, unless indicated otherwise in a credit line to the material. If material is not included in the article's Creative Commons licence and your intended use is not permitted by statutory regulation or exceeds the permitted use, you will need to obtain permission directly from the copyright holder. To view a copy of this licence, visit http://creativecommons.org/licenses/by/4.0/.

\section{References}

Abbey, E., \& Valsiner, J. (2005). Emergence of meanings through ambivalence. Forum: Qualitative Sozialforschung/ Forum: Qualitative Social Research, 6(1), 1-18.

Akpan, U. I., \& Ottu, I. F. (2011). Predicting marital satisfaction from the attachment styles and gender of a culturally and religiously homogeneous population. Gender and Behaviour, 9(1), 3656-3679.

Ash, M. A., \& Badgett, M. V. L. (2006). Separate and unequal: The effect of unequal access to employment-based health insurance on same-sex and unmarried different-sex couples. Contemporary Economic Policy, 24(4), 582-599.
Back, M. D., Penke, L., Schmukle, S. C., Sachse, K., Borkenau, P., \& Asendorpf, J. B. (2011). Why mate choices are not as reciprocal as we assume: The role of personality, flirting and physical attractiveness. European Journal of Personality, 25(2), 120-132.

Bailo, L., Vergani, L., \& Pravettoni, G. (2019). Patient preferences as guidance for information framing in a medical shared decisionmaking approach: The bridge between nudging and patient preferences. Patient Preference and Adherence, 13, 2225.

Barclay, P., \& Raihani, N. (2016). Partner choice versus punishment in human Prisoner's dilemmas. Evolution and Human Behavior, 37(4), 263-271.

Baumeister, R. F., Campbell, J. D., Krueger, J. I., \& Vohs, K. D. (2003). Does high self-esteem cause better performance, interpersonal success, happiness, or healthier lifestyles? Psychological Science in the Public Interest, 4(1), 1-44.

Beach, L. R., \& Connolly, T. (2005). The psychology of decision making: People in organizations (2nd ed.). L.R. Beach, \& T. Connolly (Eds.). SAGE publications.

Beach, L. R., \& Lipshitz, R. (2017). Why classical decision theory is an inappropriate standard for evaluating and aiding most human decision making. Decision making in aviation, 85, 835-847.

Bell, B. S., Kanar, A. M., \& Kozlowski, S. W. J. (2008). Current issues and future directions in simulated-based training. CAHRS Working Ithaca, NY: Cornell University, School of Industrial and Labor Relations. Center for Advanced Human Resource Studies, 8-13.

Ben-Akiva, M., de Palma, A., McFadden, D., Abou-Zeid, M., Chiappori, P. A., de Lapparent, M., ... Manski, C. (2012). Process and context in choice models. Marketing Letters, 23(2), 439-456.

Bentham, J. (1970). An Introduction to the Principles of Morals and Legislation (1789), ed. by J. H Burns and HLA Hart.

Biernacki, P., \& Waldorf, D. (1981). Snowball sampling: Problems and techniques of chain referral sampling. Sociological Methods \& Research, 10(2), 141-163.

Bojanić, Ž. (2014). Gender differences in expressing the job satisfaction among scientists. International Journal of Industrial Engineering and Management, 5(1), 39-44.

Bowlby, J. (1973). Attachment and loss: Vol. 2. Separation: Anxiety and anger. Basic Books.

Bowlby, J. (1982). Attachment and loss: Vol. 1. Attachment (2nd ed.). Basic Books.

Bradford, A. B., Drean, L., Sandberg, J. G., \& Johnson, L. N. (2019). They may disapprove, but I still love you: Attachment behaviors moderate the effect of social disapproval on marital relationship quality. Family Process, 59(4), 1530-1551.

Byrne, K. A., Silasi-Mansat, C. D., \& Worthy, D. A. (2015). Who chokes under pressure? The big five personality traits and decision-making under pressure. Personality and Individual Differences, 74, 22-28.

Cabanac, M. (1992). Pleasure: The common currency. Journal of Theoretical Biology, 155(2), 173-200.

Carver, C. S. (1997). Adult attachment and personality: Converging evidence and a new measure. Personality and Social Psychology Bulletin, 23(8), 865-883.

Cavanagh, J. F., Masters, S. E., Bath, K., \& Frank, M. J. (2014). Conflict acts as an implicit cost in reinforcement learning. Nature Communications, 5(1), 1-10.

Chao, X., Kou, G., Peng, Y., \& Viedma, E. H. (2021). Large-scale group decision-making with non-cooperative behaviors and heterogeneous preferences: An application in financial inclusion. European Journal of Operational Research, 288(1), 271-293.

Chen, A., Tenhunen, H., Torkki, P., Peltokorpi, A., Heinonen, S., Lillrank, P., \& Stefanovic, V. (2018). Facilitating autonomous, confident and satisfying choices: A mixed-method study of 
women's choice-making in prenatal screening for common aneuploidies. BMC Pregnancy and Childbirth, 18(1), 119.

Côté, S., \& Morgan, L. M. (2002). A longitudinal analysis of the association between emotion regulation, job satisfaction, and intentions to quit: EMOTIONAL REGULATION. Journal of Organizational Behavior, 23(8), 947-962. https://doi.org/10. 1002/job.174

Dailey, R. M., Rossetto, K. R., Pfiester, A., \& Surra, C. A. (2009). A qualitative analysis of on-again/off-again romantic relationships:"It's up and down, all around". Journal of Social and Personal Relationships, 26(4), 443-466.

Dehle, C., Larsen, D., \& Landers, J. E. (2001). Social support in marriage. American Journal of Family Therapy, 29(4), 307-324.

Deniz, M. (2011). An investigation of decision making styles and the five-factor personality traits with respect to attachment styles. Educational Sciences: Theory and Practice, 11(1), 105-113.

Dhar, R., \& Gorlin, M. (2013). A dual-system framework to understand preference construction processes in choice. Journal of Consumer Psychology, 23(4), 528-542.

Di Fabio, A., \& Palazzeschi, L. (2009). Emotional intelligence, personality traits and career decision difficulties. International Journal for Educational and Vocational Guidance, 9, 135-146.

Eisenfuhr, F. (2011). Decision making. Springer.

Ekman, P., \& Yamey, G. (2004). Emotions revealed: Recognising facial expressions: In the first of two articles on how recognising faces and feelings can help you communicate, Paul Ekman discusses how recognising emotions can benefit you in your professional life. Student BMJ, 12, 140-142.

Epstein, S. (1994). Integration of the cognitive and the psychodynamic unconscious. American Psychologist, 49(8), 709-724.

Epstein, S. (2003). Cognitive-experiential self-theory of personality. Handbook of Psychology, 159-184.

Evans, J. S. B., \& Stanovich, K. E. (2013). Dual-process theories of higher cognition: Advancing the debate. Perspectives on Psychological Science, 8(3), 223-241.

Extremera, N., Mérida-López, S., Quintana-Orts, C., \& Rey, L. (2020). On the association between job dissatisfaction and employee's mental health problems: Does emotional regulation ability buffer the link? Personality and Individual Differences, 155, 109710.

Feeney, J. A., \& Noller, P. (1992). Attachment style and romantic love: Relationship dissolution. Australian Journal of Psychology, 44(2), 69-74.

Finucane, M. L., Alhakami, A., Slovic, P., \& Johnson, S. M. (2000). The affect heuristic in judgments of risks and benefits. Journal of Behavioral Decision Making, 13(1), 1-17.

Firth, L., Mellor, D. J., Moore, K. A., \& Loquet, C. (2004). How can managers reduce employee intention to quit? Journal of managerial psychology, 19(2), 170-187.

Fortin-Guichard, D., Laflamme, V., Julien, A. S., Trottier, C., \& Grondin, S. (2020). Decision-making and dynamics of eye movements in volleyball experts. Scientific reports, 10(1), 1-14.

Fossa, P., Cornejo, C., Carré, D., \& Pontificia Universidad Católica de Chile, Chile. (2016). Semiotic analysis of empathic and nonempathic interaction sequences: Microgenetic study. Psicologia USP, 27(3), 441-449. https://doi.org/10.1590/0103-6564201500 16

Franco, M., \& Sanches, C. (2016). Influence of emotions on decisionmaking. International Journal of Business and Social Research, 6(1), 40-62.

Franco, M., Hsiao, Y. S., Gnilka, P. B., \& Ashby, J. S. (2019). Acculturative stress, social support, and career outcome expectations among international students. International Journal for Educational and Vocational Guidance, 19(2), 275-291.

Frey, D. F., \& Pimentel, R. A. (1978). Principal component analysis and factor analysis. In: P.W. Colgan (Ed.), Quantitative ethology. New York, USA: John Wiley and Sons.
Galotti, K. M. (1989). Approaches to studying formal and everyday reasoning. Psychological Bulletin, 105(3), 331.

Galotti, K. M. (2005). Making decisions that matter: How people face important life choices. Psychology Press.

Galotti, K. M. (2007). Decision structuring in important real-life choices. Psychological Science, 18(4), 320-325.

Galotti, K. M. (2017). Cognitive psychology in and out of the laboratory. Sage Publications.

Galotti, K. M., \& Umscheid, V. A. (2019). Students choosing courses: Real-life academic decision making. The American Journal of Psychology, 132(2), 149-159.

Gati, I., Gadassi, R., Saka, N., Hadadi, Y., Ansenberg, N., Friedmann, R., \& Asulin-Peretz, L. (2011). Emotional and personalityrelated aspects of career decision-making difficulties: Facets of career indecisiveness. Journal of Career Assessment, 19(1), $3-20$.

Guan, Y., Deng, H., Fan, L., \& Zhou, X. (2021). Theorizing personenvironment fit in a changing career world: Interdisciplinary integration and future directions. Journal of Vocational Behavior, $126,103557$.

Hamarta, E. (2004). Üniversite öğrencilerinin yakın ilişkilerindeki bazı değişkenlerin (benlik saygısı, depresyon ve saplantılı dÜşÜnme) bağlanma stilleri açısından incelenmesi. Yayımlanmamış doktora tezi, Selçuk Üniversitesi, Sosyal Bilimler EnstitÜsÜ, Konya.

Hammock, G., \& Richardson, D. S. (2011). Love attitudes and relationship experience. The Journal of Social Psychology, 151(5), 608-624.

Hartley, C. A., \& Phelps, E. A. (2012). Anxiety and decision-making. Biological Psychiatry, 72(2), 113-118.

Hatch, A. (2017). Saying "I Don't" to matrimony: An investigation of why long-term heterosexual Cohabitors choose not to marry. Journal of Family Issues, 38(12), 1651-1674. https://doi.org/10. $1177 / 0192513 X 15576200$

Hazan, C., \& Shaver, P. R. (1990). Love and work: An attachmenttheoretical perspective. Journal of Personality and Social Psychology, 59(2), 270.

Hepler, T. J., \& Feltz, D. L. (2012). Path analysis examining self-efficacy and decision-making performance on a simulated baseball task. Research Quarterly for Exercise and Sport, 83(1), 55-64.

Herman, A. M., Critchley, H. D., \& Duka, T. (2018). Risk-taking and impulsivity: The role of mood states and interoception. Frontiers in Psychology, 9, 1625.

Hertwig, R., \& Erev, I. (2009). The description-experience gap in risky choice. Trends in Cognitive Sciences, 13(12), 517-523.

Hirsh, J. B., \& Peterson, J. B. (2009). Extraversion, neuroticism, and the prisoner's dilemma. Personality and Individual Differences, 46(2), 254-256.

Isik, E. (2013). Perceived social support and locus of control as the predictors of vocational outcome expectations. Educational Sciences: Theory and Practice, 13(3), 1426-1430.

John, O. P., Donahue, E. M., \& Kentle, R. L. (1991). The big five inventory-Versions $4 a$ and 54. University of California, Berkeley, Institute of Personality and Social Research.

Jones, J. T., \& Cunningham, J. D. (1996). Attachment styles and other predictors of relationship satisfaction in dating couples. Personal Relationships, 3(4), 387-399.

Judge, T. A., \& Bono, J. E. (2001). Relationship of core self-evaluations traits-Self-esteem, generalized self-efficacy, locus of control, and emotional stability-With job satisfaction and job performance: A meta-analysis. Journal of Applied Psychology, $86(1), 80$

Kahneman, D., \& Tversky, A. (1979). Prospect theory: An analysis of decision under risk. Econometrica, 47(2), 263-291.

Kahneman, D., \& Frederick, S. (2002). Representativeness revisited: Attribute substitution in intuitive judgment. Heuristics and biases: The psychology of intuitive judgment, 49, 81 . 
Kahneman, D., \& Tversky, A. (2013). Prospect theory: An analysis of decision under risk. In Handbook of the fundamentals of financial decision making: Part I (pp. 99-127).

Khatri, V., Samuel, B. M., \& Dennis, A. R. (2018). System 1 and system 2 cognition in the decision to adopt and use a new technology. Information \& Management, 55(6), 709-724.

Kim, T. K. (2015). T test as a parametric statistic. Korean Journal of Anesthesiology, 68(6), 540.

Kirkpatrick, L. A., \& Davis, K. E. (1994). Attachment style, gender, and relationship stability: A longitudinal analysis. Journal of Personality and Social Psychology, 66(3), 502.

Klein, G. A. (2017). Sources of power: How people make decisions. MIT press.

Koehler, D. J., Langstaff, J., \& Liu, W. Q. (2015). A simulated financial savings task for studying consumption and retirement decision making. Journal of Economic Psychology, 46, 89-97.

Kondylakis, H., Bucur, A., Dong, F., Renzi, C., Manfrinati, A., Graf, N., ... \& Tsiknakis, M. (2017). iManageCancer: Developing a platform for Empowering patients and strengthening self-management in cancer diseases. In 2017 IEEE 30th International Symposium on Computer-Based Medical Systems (CBMS) (pp. 755-760). IEEE.

Kou, G., Ergu, D., \& Shang, J. (2014). Enhancing data consistency in decision matrix: Adapting Hadamard model to mitigate judgment contradiction. European Journal of Operational Research, 236(1), 261-271.

Lauriola, M., \& Levin, I. P. (2001). Personality traits and risky decision-making in a controlled experimental task: An exploratory study. Personality and Individual Differences, 31(2), 215-226.

Lawson, K. L., \& Pierson, R. A. (2007). Maternal decisions regarding prenatal diagnosis: Rational choices or sensible decisions? Journal of Obstetrics and Gynaecology Canada, 29(3), 240-246.

Lee, W. S., \& Selart, M. (2012). The impact of emotions on trust decisions. Handbook on psychology of decision-making. Nova Science.

Lerner, J. S., Li, Y., Valdesolo, P., \& Kassam, K. S. (2015). Emotion and decision making. Annual Review of Psychology, 66, 799823. https://doi.org/10.1146/annurev-psych-010213-115043

Levin, I. P., Gaeth, G. J., Schreiber, J., \& Lauriola, M. (2002). A new look at framing effects: Distribution of effect sizes, individual differences, and types of effects. Organizational Behavior and Human Decision Processes, 88, 411-429.

Levine, D. S. (2019). One or two minds? Neural network modeling of decision making by the unified self. Neural Networks, 120, 74-85.

Lieberman, M. D., Gaunt, R., Gilbert, D. T., \& Trope, Y. (2002). Reflexion and reflection: A social cognitive neuroscience approach to attributional inference. In M. P. Zanna (Ed.), Advances in experimental social psychology (Vol. 34, pp. 199-249). Academic Press.

Lin, W. F., Li, T. S., \& Chen, L. H. (2017). Sacrifice in a supportive marriage: Social support as a moderator buffers the negative effects of sacrifice in marriage. Journal of Happiness Studies, $18(2), 575-589$.

Liu, H., Zhang, X., Chang, R., \& Wang, W. (2017). A research regarding the relationship among intensive care nurses' selfesteem, job satisfaction and subjective well-being. International journal of nursing sciences, 4(3), 291-295.

Loewenstein, G. F., Weber, E. U., Hsee, C. K., \& Welch, N. (2001). Risk as feelings. Psychological Bulletin, 127(2), 267-286. https://doi.org/10.1037/0033-2909.127.2.267

Loewenstein, G., O'Donoghue, T., \& Bhatia, S. (2015). Modeling the interplay between affect and deliberation. Decision, 2(2), 55.
Lucchiari, C., Masiero, M., Botturi, A., \& Pravettoni, G. (2016). Helping patients to reduce tobacco consumption in oncology: A narrative review. SpringerPlus, 5(1), 1136.

Ludvig, E. A., \& Spetch, M. L. (2011). Of black swans and tossed coins: Is the description-experience gap in risky choice limited to rare events? PLoS One, 6(6), e20262.

Madan, C. R., Ludvig, E. A., \& Spetch, M. L. (2014). Remembering the best and worst of times: Memories for extreme outcomes bias risky decisions. Psychonomic Bulletin \& Review, 21(3), 629-636.

Maskens, M. (2015). Bordering intimacy: The fight against marriages of convenience in Brussels. The Cambridge journal of anthropology, 33(2), 42-58.

Mazzocco, K., Masiero, M., Carriero, M. C., \& Pravettoni, G. (2019). The role of emotions in cancer patients' decisionmaking. ecancermedicalscience, 13.

Meijers, F., Kuijpers, M., \& Gundy, C. (2013). The relationship between career competencies, career identity, motivation and quality of choice. International Journal for Educational and Vocational Guidance, 13(1), 47-66.

Metzger, R. L. (1976). A reliability and validity study of the statetrait anxiety inventory. Journal of Clinical Psychology, 32(2), 276-278.

Meyer, D. D., Jones, M., Rorer, A., \& Maxwell, K. (2015). Examining the associations among attachment, affective state, and romantic relationship quality. The Family Journal, 23(1), 18-25.

Mughal, S., Walsh, J., \& Wilding, J. (1996). Stress and work performance: The role of trait anxiety. Personality and Individual Differences, 20(6), 685-691.

Ngambeki, I., \& Dalrymple, O., \& Evangelou, D. (2008). Decision Making In First Year Engineering: Exploring How Students Decide About Future Studies And Career Pathways. Paper presented at 2008 Annual Conference \& Exposition, Pittsburgh, Pennsylvania. https://doi.org/10.18260/1-2--4247.

Noël, X., Brevers, D., \& Bechara, A. (2013). A triadic neurocognitive approach to addiction for clinical interventions. Frontiers in Psychiatry, 4, 179.

Oatley, K., Keltner, D., \& Jenkins, J. M. (2006). Understanding emotions. Blackwell publishing.

Pacheco-Barrios, K., \& Fregni, F. (2020). Evidence-based decision making during COVID-19 pandemic. Principles and practice of clinical research (2015), 6(1), 1.

Paivio, A. (1990). Mental representations: A dual coding approach. Oxford University Press.

Palomares, I., Liu, J., Xu, Y., \& Martínez, L. (2012). Modelling experts' attitudes in group decision making. Soft Computing, 16(10), 1755-1766.

Pedrabissi, L., \& Santinello, M. (1989). Verifica della validità dello STAI forma Y di Spielberger. Giunti Organizzazioni Speciali.

Pilgeram, R., \& Amos, B. (2015). Beyond "inherit it or marry it": Exploring how women engaged in sustainable agriculture access farmland: Beyond "inherit it or marry it.". Rural Sociology, 80(1), 16-38. https://doi.org/10.1111/ruso.12054

Pomytkina, L., Gudmanian, A., Kovtun, O., \& Yahodzinskyi, S. (2020). Personal choice: Strategic life decisionmaking and conscience. In E3S Web of Conferences (Vol. 164, p. 10021). EDP Sciences.

Porter, A. M. W. (1999). Misuse of correlation and regression in three medical journals. Journal of the Royal Society of Medicine, 92(3), 123-128. https://doi.org/10.1177/014107689909200306

Presnilla-Espada, J. (2014). An exploratory study on simulated teaching as experienced by education students. Universal Journal of Educational Research, 2(1), 51-63.

Prezza, M., \& Principato, M. C. (2002). La rete sociale e il sostegno sociale In: Prezza M, Santinello M, editors. Conoscere la comunità. Bologna (Italy): Il Mulino, 193-233. 
Prezza, M., Trombaccia, F. R., \& Armento, L. (1997). La scala dell'autostima di Rosenberg: traduzione e validazione italiana. Bollettino di Psicologia Applicata, 223, 35-44.

Raffagnino, R., \& Puddu, L. (2018). Love styles in couple relationships: A literature review. Open Journal of Social Sciences, 6(12), 307-330.

Richards, D. W., Fenton-O'Creevy, M., Rutterford, J., \& Kodwani, D. G. (2018). Is the disposition effect related to investors' reliance on system 1 and system 2 processes or their strategy of emotion regulation? Journal of Economic Psychology, 66, 79-92.

Riedo, V., Kraiczy, N. D., \& Hack, A. (2019). Applying person-environment fit theory to identify personality differences between prospective social and commercial entrepreneurs: An explorative study. Journal of Small Business Management, 57(3), 989-1007.

Roccato, M., \& Tartaglia, S. (2003). Un adattamento italiano della measure of attachment qualities di Carver. An Italian adaptation of Carver's measure of attachment qualities. Testing Psicometria Metodologia, 10, 65-78.

Rogante, E., Sarubbi, S., Lamis, D. A., Canzonetta, V., Sparagna, A., De Angelis, V., ... Pompili, M. (2019). Illness perception and job satisfaction in patients suffering from migraine headaches: Trait anxiety and depressive symptoms as potential mediators. Headache: The Journal of Head and Face Pain, 59(1), 46-55.

Rosenberg, M. (1965). Society and the adolescent self-image. Princeton University Press.

Rosenberg, M. (2015). Society and the adolescent self-image. Princeton University Press.

Roxburgh, S. (1999). Exploring the work and family relationship: Gender differences in the influence of parenthood and social support on job satisfaction. Journal of Family Issues, 20(6), 771-788.

Rozin, P., \& Hormes, J. M. (2010). Psychology and sensory marketing, with a focus on food. In A. Krishna (Ed.), Sensory marketing: Research on the sensuality of products (p. 303-321). Routledge/ Taylor \& Francis Group.

Sanfey, A. G. (2007). Social decision-making: Insights from game theory and neuroscience. Science, 318(5850), 598-602.

Saquib, N., Zaghloul, M. S., Saquib, J., Al-Homaidan, H. T., Al-Mohaimeed, A., \& Al-Mazrou, A. (2019). Association of cumulative job dissatisfaction with depression, anxiety and stress among expatriate nurses in Saudi Arabia. Journal of Nursing Management, 27(4), 740-748.

Schaefer, P. S., Williams, C. C., Goodie, A. S., \& Campbell, W. K. (2004). Overconfidence and the big five. Journal of Research in Personality, 38(5), 473-480.

Scheffe, H. (1999). The analysis of variance (Vol. 72). Wiley.

Sebri, V., Triberti, S., \& Pravettoni, G. (2021). The self's choice: Priming attentional focus on bodily self promotes loss frequency bias. Current Psychology, 1-12.

Shafir, E., Tversky, A., Smith, E. E., \& Osherson, E. E. D. (2002). Decision making (pp. 601-620). Foundations of Cognitive Psychology.

Skatova, A., \& Ferguson, E. (2014). Why do different people choose different university degrees? Motivation and the choice of degree. Frontiers in Psychology, 5, 1244.

Sloman, S. A. (1996). The empirical case for two systems of reasoning. Psychological Bulletin, 119(1), 3 .

Smith, R., \& Klases, A. (2016). Predictors of love attitudes: The contribution of cultural orientation, gender attachment style, relationship length and age in participants from the UK and Hong Kong. Interpersonal. An International Journal on Personal Relationships, 10, 90-108.
Smith, A. D., \& Manna, D. R. (2005). Exploring why people love their jobs: A multi-industry case study. Journal of Business \& Economics Research (JBER), 3(3), 27-32.

Spielberger, C. D., Gorsuch, R. L., Lushene, P. R., Vagg, P. R., \& Jacobs, A. G. (1983). Manual for the state-trait anxiety inventory (form Y) (pp. 4-6). Consulting Psychologists Press.

Stamos, A., Bruyneel, S., De Rock, B., Cherchye, L., \& Dewitte, S. (2018). A dual-process model of decision-making: The symmetric effect of intuitive and cognitive judgments on optimal budget allocation. Journal of Neuroscience, Psychology, and Economics, 11(1), 1.

Stanovich, K. E., \& West, R. F. (2000). Individual differences in reasoning: Implications for the rationality debate? Behavioral and Brain Sciences, 23(5), 645-665.

Stine, R. A., Foster, D., \& Foster, D. P. (2011). Statistics for business: Decision making and analysis. Addison-Wesley.

Stolyarov, N. O., Petrenko, E. S., Serova, O. A., \& Umuralieva, A. S. (2019). The digital reality of the modern economy: New actors and new decision-making logic. In Institute of Scientific Communications Conference (pp. 882-888). Springer.

Tao, Y., Cai, Y., Rana, C., \& Zhong, Y. (2020). The impact of the extraversion-introversion personality traits and emotions in a moral decision-making task. Personality and Individual Differences, 158, 109840.

Tversky, A., \& Kahneman, D. (1974). Judgment under uncertainty: Heuristics and biases. Science, 185, 1124-1131.

Tversky, A., \& Kahneman, D. (1981). The framing of decisions and the psychology of choice. Science, 211, 453-458.

Ubbiali, A., Chiorri, C., Hampton, P., \& Donati, D. (2013). Italian big five inventory. Psychometric properties of the italian adaptation of the big five inventory (BFI). Bollettino di Psicologia Applicata, 266, 37-48.

van Vianen, A. E. (2018). Person-environment fit: A review of its basic tenets. Annual Review of Organizational Psychology and Organizational Behavior, 5, 75-101.

Wagoner, B., Brescó de Luna, I., \& Zadeh, S. (2020). Memory in the wild. Information Age Publishing, Inc..

Wiswall, M., \& Zafar, B. (2015). Determinants of college major choice: Identification using an information experiment. The Review of Economic Studies, 82(2), 791-824.

Wray, H. (2006). An ideal husband-marriages of convenience, moral gate-keeping and immigration to the UK. Eur. J. Migration \& L., 8,303 .

Wray, L. D., \& Stone, E. R. (2005). The role of self-esteem and anxiety in decision making for self versus others in relationships. Journal of Behavioral Decision Making, 18(2), 125-144.

Yang, P. (2019). A life journal into the future: Development of a storytelling approach for establishing career identity and agency in career counselling. Innovations in Education and Teaching International, 56(6), 700-710.

Zimet, G. D., Dahlem, N. W., Zimet, S. G., \& Farley, G. K. (1988). The multidimensional scale of perceived social support. Journal of Personality Assessment, 52, 30-41.

Publisher's Note Springer Nature remains neutral with regard to jurisdictional claims in published maps and institutional affiliations. 